\title{
Para pensar o colonial e o pós-colonial: Fronteiras para a teoria e a crítica literárias
}

Fábio Salem Daie ${ }^{1}$

RESUMO: O presente artigo investiga as diferenças e inflexões entre algumas das formulações centrais da teoria pós-colonial inglesa e autores latino-americanos que se dedicaram a pensar o estatuto da cultura e suas trocas simbólicas em momentos diversos. Busca-se relacionar historicamente os paradigmas teóricos dessa teoria pós-colonial à ascensão neoliberal das décadas de 1980-1990, chamando a atenção para sua ênfase "culturalista", tal como designado pelo crítico inglês Terry Eagleton.

ABSTRACT: This article investigates the differences and inflections between some of the core formulations of English post-colonial theory and Latin American authors who have dedicated themselves to think the cultural status and its symbolic exchanges at various moments. We seek to historically relate the theoretical paradigms of the postcolonial theory to the neoliberal rise during decades of 1980-1990, drawing attention to its "culturalist" emphasis, as designated by the British critic Terry Eagleton.

PALAVRAS-CHAVE: Teoria pós-colonial; neoliberalismo; América Latina; modernidade. KEYWORDS: Postcolonial theory ; Neoliberalism ; Latin America; Modernity.

A tendência de encarar a arte e a crítica como instâncias autônomas da sociedade encontra raízes ainda no fim da sociedade aristocrática e na ascensão da burguesia (como se sabe: a inglesa, no século XVII; a francesa, no século XVIII), que marca o surgimento do Estado-nação moderno e suas primeiras conotações com a questão da identidade nacional. No âmbito da literatura, tal tendência está ligada à ascensão de outra tradição especificamente burguesa: a categoria analítica da Estética. Raymond Williams recorda que tal abstração conceitual expressa certa divisão específica do trabalho nessas sociedades, e que o "estético" assumiria a arte como "um tipo de produção considerado como separado da norma produtiva burguesa dominante: a feitura de mercadorias" (WILLIAMS, 1979, p. 154), obstruindo a percepção de que toda criação artística está, no fundo, relacionada intrinsecamente com seus processos materiais.

Iná Camargo Costa, por sua vez, afirma que "artistas caíram e até hoje continuam caindo na conversa de que são indivíduos livres. Para a maioria das artes isso nunca foi verdade, como é o caso da arquitetura, da música, da dança e do teatro" (COSTA, 2008,

\footnotetext{
${ }^{1}$ Doutorando no programa de Estudos Comparados de Literaturas de Língua Portuguesa (DLCV-USP), realiza pesquisa atual intitulada "Formação Periférica: Forma Narrativa como Crítica Histórica".
} 
p. 102). Certamente, essa dificuldade de identificar os laços escusos que ligam a arte às suas bases materiais ganha fôlego quando se trata da criação literária, dada a especificidade das suas condições de produção quase sempre individuais. Fredric Jameson, ao abordar a arte pós-moderna, em Pós-modernismo ou a Lógica Cultural do Capitalismo Tardio (1991), bem apontou que a arquitetura havia sido a primeira a formular novas concepções artísticas em função de seu enfronhamento (maior que o de qualquer outra arte) com os negócios do mercado. Ainda assim, tanto Williams quanto Iná Camargo lembram que o aparecimento da indústria cinematográfica, no século XX, deu cabo da possibilidade de se pensar a produção individual de maneira independente de quaisquer determinações externas. O termo "indústria", aplicado ao cinema, certamente recobra algo dessa impreterível relação com o mundo.

Se comparada com a arquitetura e o cinema, vemos que há certa dificuldade na tarefa de pensar a produção literária neste nível fundamental. Ángel Rama abordou a questão no texto "Dez problemas para o romancista latino-americano" (1982), onde observa que a literatura constitui a expressão cultural de um alto grau de especialização das sociedades modernas, porém apartada ainda do patamar atingido por atividades ligadas à educação, "conseqüência de uma determinada valoração (uma precisa visão de futuro) que o corpo social assume e que produz um investimento da renda nacional para assegurá-las e até propiciá-las" (RAMA, 2001, p. 54).

Deixada, assim, à volubilidade do mercado, a literatura trará à tona essas condições de sobrevivência através do trabalho criativo do artista. Neste sentido, como poderíamos nos referir a um sistema literário ${ }^{2}$ ? Talvez a primeira pergunta que se deva formular é em que medida o surgimento de conglomerados editoriais permite a liberação do escritor de outras funções e quais as consequências dessa especialização. Outra pergunta seria como a promoção - cada vez mais imediata - de sua obra para além das fronteiras nacionais marca o desenvolvimento de seu trabalho e do próprio sistema literário em suas trocas simbólicas mútuas. Por fim (e normalmente esquecido), seria ainda necessário avaliar o impacto sobre a literatura de um sistema de produção baseado na mercantilização da arte (contratos editoriais), em detrimento de fomentos públicos à arte, onde o Estado toma para si a responsabilidade de promover a cultura. Como nos lembra Chin-Tao Wu, "ao premiar o trabalho artístico, as corporações vêm tentando se

\footnotetext{
2 Pensamos aqui, obviamente, no conceito de "sistema literário" como expresso por Antonio Candido em "Formação da Literatura Brasileira" e "Literatura e Sociedade", ou seja: aquela noção estrutural que articula autores, obras e público leitor.
} 
colocar diretamente no centro do palco e elevar-se à condição de árbitros do bom gosto da cultura em nossos dias" (WU, 2006, p. 26).

Tal afirmação vem bater de frente com uma das concepções de Stuart Hall - a de modernidade vernácula (HALL, 2003) - segundo a qual as culturas locais, ainda que submetidas ao imperialismo cultural (sobretudo o dos Estados Unidos), possuem a capacidade de retrabalhar tais elementos homogeneizantes, transformando-os com elementos locais em expressão artística original. A pergunta que se impõe aqui é: se o vetor da cultura dominante se apoia no grande capital, sendo dependente dele, por que o vetor da cultura local estaria a salvo de tais determinações numa sociedade hegemonicamente conformada neste molde (do mercado e do dinheiro)? O que queremos dizer é que, se a expressão da cultura local não possui os meios equivalentes de automanutenção, está claro que este "retrabalhar" do imperialismo cultural corre o risco de ser mero exercício de sobrevivência. Numa época de mundialização do capital, se o local vive dentro do global é mais como "resistência" do que como mera "fusão" isenta de uma luta de forças ${ }^{3}$.

\section{Defesa das categorias socioeconômicas}

No nível do Atlântico negro ${ }^{4}$ (GILROY, 2001), destruídos os impérios coloniais, encerradas as ditaduras latino-americanas, interrompidas as forças de promoção do Welfare State pela social-democracia europeia desde a derrocada do fascismo e - fora do Atlântico, mas com reverberações para dentro dele - tombados os últimos destroços da União Soviética, testemunhou-se uma ascensão vertiginosa do liberalismo, pela primeira vez em escala mundial (daí seu aspecto "novo", ou seja, neo-liberal). Isto afetou profundamente a totalidade da vida dessas nações, inclusive a área da educação e da cultura.

Ao pensar um sistema literário, é necessário ter em mente algumas das correntes que teorizaram, nos últimos anos, as trocas simbólicas através das fronteiras nacionais. Entre essas trocas, aquela de imigrados (ou filhos de imigrados) de ex-colônias inglesas para dentro de Grã-Bretanha e Estados Unidos - e que conta com nomes como Stuart

\footnotetext{
${ }^{3}$ Voltaremos a este ponto logo adiante, quando da discussão entre os conceitos de "multi-centralidade", ligado a esta corrente teórica do pós-colonialismo, e de "centro-periferia".

${ }^{4}$ Para utilizar um conceito geográfico-metafórico que Paul Gilroy propõe como chave para pensar os movimentos diaspóricos e as trocas culturais no ocidente pré e pós-colonial.
} 
Hall, Paul Gilroy e Homi Bhabha - é a principal defensora do que podemos chamar de "o crepúsculo dos Estados-nação" ao fim do breve século vinte. Parece-nos que é preciso apontar alguns dos paradigmas teóricos de Hall e outros que se coadunam, em sua conformação histórica, com algumas das principais forças do conservadorismo econômico thatcherista (1979-1990), na Inglaterra, e da era Reagan (1981-1989), nos Estados Unidos. Como explica Eagleton:

\begin{abstract}
A teoria pós-colonial não é apenas o produto do multiculturalismo e da descolonização. Reflete, também, uma passagem histórica do nacionalismo revolucionário do Terceiro Mundo, que refluiu na década de 1970, para um contexto 'pós-revolucionário' no qual o poder das corporações transnacionais parece indestrutível. Desta maneira, grande parte dos escritos pós-coloniais ajusta-se bastante bem às desconfianças pós-modernas das organizações políticas de massa (...). (EAGLETON, 1997, p. 324).
\end{abstract}

A escalada do capital privado nas décadas de 1980 e 1990 foi marcada, na área da cultura, pelo processo de precarização do Estado e subsequente privatização cultural. Ainda segundo Iná Camargo, "Thatcher e Reagan revogaram a convicção socialdemocrata de que o acesso às artes, bem como a qualquer outro serviço público oferecido pelo Estado, é um direito fundamental do cidadão" (COSTA, 2008, p.14).

Nas áreas política e econômica, a regra foi a expansão da influência dos países capitalistas (sobretudo os Estados Unidos) sobre regiões recém-descolonizadas ao redor do globo, além dos territórios emersos do colapso da URSS. É neste contexto do multinacionalismo corporativo que se desenvolverá boa parte da teoria pós-colonial inglesa e norte-americana, tendo entre suas concepções-chave o suposto enfraquecimento das fronteiras "nacionalistas" dos Estados-nação e uma perspectiva das trocas culturais no Ocidente sobre um eixo multi-central (o que, como dito, Hall chamará de "modernidades vernáculas") e não mais centro-periférico. De fato, quando Gilroy escreve contra "as limitações políticas reveladas pelas formas essencialistas de conceituar a cultura, a identidade e a identificação", afirma que "a ideia de diáspora se tornou agora integral a este empreendimento político, histórico e filosófico descentrado, ou, mais precisamente, multi-centrado" (GILROY, 2001, p. 17). Seu ataque ao conceito de Estado- 
nação está intimamente ligado à sua proposta de uma "estrutura rizomórfica ${ }^{5}$ e fractal da formação transcultural e internacional a que chamo Atlântico Negro":

Ultrapassar essas perspectivas nacionais e nacionalistas tornou-se essencial por duas razões adicionais. A primeira origina-se da obrigação urgente de reavaliar o significado do Estado-nação moderno como unidade política, econômica e cultural. Nem as estruturas políticas, nem as estruturas econômicas de dominação coincidem mais com as fronteiras nacionais. (...) A segunda razão diz respeito à popularidade trágica de ideias sobre a integridade e a pureza das culturas. Em particular, ela diz respeito à relação entre nacionalidade e etnia. (GILROY, 2001, p.42)

Por sua vez, Hall enxerga na proposta do Atlântico negro, de Gilroy, "uma potente contranarrativa à inserção do Caribe nas histórias nacionais europeias, trazendo à tona as trocas laterais e as 'semelhanças familiares' na região (...) que 'a história nacionalista obscurece"" (HALL, 2003, p.36). Tratando da nova fase de ascensão do neoliberalismo que mencionamos acima -, o autor afirma que este sistema transnacional "tem seu 'centro' cultural em todo lugar e em lugar nenhum":

Aqui, o referencial nacional não é muito útil. Os Estados-nação impõem fronteiras rígidas dentro das quais se espera que as culturas floresçam. (...) A questão é se ele [o Estado-nação] ainda constitui uma estrutura útil para a compreensão das trocas culturais entre as diásporas negras. (HALL, 2003, p. 35)

Por fim, Homi Bhabha dá sua contribuição à problemática do Estado-nação: “de certa forma é em oposição à certeza histórica e à natureza estável desse termo [nacionalismo] que procuro escrever sobre a nação ocidental como uma forma obscura e ubíqua de viver a localidade da cultura" (BHABHA, 2005, p. 199).

Ao reconhecermos a importância, para pensar qualquer sistema literário, de uma visão "não essencialista da cultura" e de um aparato conceitual centrado nas trocas simbólicas supranacionais, alertamos no entanto para algumas das implicações dessa perspectiva teórica que, segundo acreditamos, subestima a importância do momento histórico do Estado-nação. Embalada na ascensão de organismos e estruturas ditas supranacionais na década de 1990, essas formulações parecem subestimar o peso do poder

\footnotetext{
${ }^{5}$ O termo é derivado do conceito de "rizoma", criado por Gilles Deleuze e Félix Guattari.
} 
nacional seja dentro de instituições como o Banco Mundial, seja no Parlamento Europeu que emerge com a consolidação da União Europeia. Mais recentemente, o filósofo francês Jacques Rancière considerou que "o suposto enfraquecimento dos Estados-nação no espaço europeu ou mundial é uma perspectiva enganosa” (RANCIÈRE, 2014, p. 104) pois, ao contrário das assunções costumeiras, não existiria verdadeiro antagonismo entre a ascensão do capitalismo internacional e o fortalecimento desses Estados como unidades políticas, governadas em favor das elites nacionais (assertiva, aliás, que ecoa a tese apresentada por Giovanni Arrighi em seu $O$ Longo Século $X X$, de 1994). Além dessas considerações políticas, também no nível social se observa que "os mesmos Estados que abdicam de seus privilégios diante da exigência da livre circulação dos capitais imediatamente os recuperam para fechar suas fronteiras à livre circulação dos pobres do planeta em busca de trabalho" (RANCIÈRE, 2014, pp. 104-105).

No que tange o problema das trocas culturais, ao proporem um sistema “multicentral" (de "modernidades vernáculas"), ao invés de "centro-periférico", parecenos que os teóricos da corrente pós-colonial inglesa acabam por deformar a dinâmica real do sistema econômico mundial. Atento a este movimento, Benjamin Abdala Jr. comenta em Margens da Cultura:

Em razão do caráter geopolítico que envolve a globalização neoliberal, que vincula poder de Estado aos das corporações supranacionais, parece-nos que noções como centro e periferia continuam a ser ainda imprescindíveis ao pensamento crítico. (...) A consideração dessa desterritorialização relativa é necessária, mas evidentemente esses nós situam-se em áreas geográficas determinadas, formando aí um sentido contextual que determina a direção vetorial dos fluxos. (ABDALA, 2004, p.13)

Benjamin Abdala ressalta a importância das articulações comunitárias como tentativa de resistência à cooptação dessas forças multinacionais desagregadoras, constatando que "os indivíduos continuam a projetar suas expectativas nos horizontes nacionais, e os Estados continuam a ser instâncias de intermediação do indivíduo com o mundo" (2004, p. 13). Além disso, gostaríamos também de sugerir que tais concepções teóricas, que utilizam como argumento as atividades das corporações transnacionais e o surgimento de organizações supranacionais como a União Europeia (HALL, 2003, p. 36) para minorar o papel das fronteiras do Estado-nação, parecem ignorar outros fenômenos 
como a resistência da indústria cinematográfica francesa ao imperialismo cultural norteamericano, a xenofobia dentro de quase todas as fronteiras nacionais a grupos específicos de imigrantes, o próprio embate político-econômico entre Estados sobre os rumos da União Europeia, etc.

Oriundos de colônias que ainda na década de 1950 negociaram sua libertação com a Inglaterra; filhos, às vezes, de abastadas famílias de uma elite colonial preparada e educada pelas próprias universidades inglesas para assumir a administração de seus países depois da independência; poupados das consequências mais nefastas do colonialismo mais pobre entre as metrópoles europeias, cujas monoculturas em larga escala levaram a um dos maiores êxodos da África e cuja precariedade econômica determinou que seus povos se lançassem contra "a maior máquina de guerra" dentro do continente 6 : aos teóricos pós-coloniais do mundo anglo-saxão é talvez mais admissível não pensar na "fonte do trauma" (GILROY, 2001, p. 86) do que àqueles - de Angola, Moçambique, Cabo-Verde - egressos de décadas de guerras de independência e guerras civis e empobrecidos pela ortodoxia neoliberal que comandou, em 1980 e 1990, os planos de ajuste estrutural.

É interessante também notar que estes pesquisadores pós-coloniais se valem direta e indiretamente - de conceitos criados e utilizados pelo antropólogo cubano Fernando Ortiz e pelo crítico uruguaio Ángel Rama. A referência direta e mais óbvia, o conceito de transculturação, foi criada por Ortiz no clássico Contrapunteo Cubano del Tabaco y del Azúcar, de 1940, como oposição ao termo "aculturação", utilizado por diversos antropólogos à época. Para Ortiz, o conceito de "aculturação" não daria conta da complexidade do processo de trocas simbólicas envolvido no contato entre duas civilizações. Desde então, de Bronislaw Malinowski, um dos pais fundadores da Antropologia no século XX, até os estudiosos da Teoria Literária e dos Estudos Culturais, o conceito de transculturação vem sendo utilizado para descrever esse tipo de contato ${ }^{7}$.

No entanto, temos razões para sugerir aqui que este conceito de transculturação, tão constantemente referido a Ortiz, provavelmente teve origem - sem o mesmo nome, claro - na obra de um autor do século XIX, o antropólogo norte-americano Frederick

\footnotetext{
${ }^{6}$ Um estudo sobre a precariedade econômica da dominação colonial portuguesa que acabou por determinar a radicalidade da violência pelo uso externo do poderio militar está em Portugal e o Fim do Ultracolonialismo, de Perry Anderson (Editora Civilização Brasileira, 1966).

${ }^{7}$ Como se sabe, o próprio Rama transpôs o conceito de Ortiz para seus trabalhos de Teoria Literária.
} 
Jackson Turner. Em sua tese ${ }^{8}$, referindo-se à marcha para o oeste norte-americano, Turner divide o processo cultural na fronteira nacional em três momentos: de adaptação do chamado "adventício" às condições do meio; em seguida, de transformação desse meio a partir de conquistas legadas pela civilização europeia; e finalmente o "rearranjo" da tradição europeia frente às condições de vida locais. Em suma, Turner acaba por interpretar a história norte-americana "como um recuo a padrões primitivos para a posterior retomada de uma evolução rumo à civilização, mas que, graças ao primeiro momento, não reproduz a velha Europa e aponta para uma civilização nova" (WEGNER, 2000, p. 101). Ora, no ensaio "Os Processos de transculturação na narrativa latinoamericana" (1974), Rama manifesta sua concordância com o cubano Fernando Ortiz quanto à utilização do termo transculturação que refaz, resumidamente, o processo acima descrito:

\begin{abstract}
Entendemos que o vocábulo transculturação expressa melhor as diferentes fases do processo transitivo de uma cultura a outra, porque este não consiste apenas em adquirir uma cultura, que é o que a rigor indica o vocábulo anglo-americano aculturação, mas implica também necessariamente a perda ou o desligamento de uma cultura precedente, o que poderia ser chamado de uma parcial desaculturação, e, além disso, significa a conseqüente criação de novos fenômenos culturais que poderiam ser denominados neoculturação. (2001, p.216)
\end{abstract}

Como fica patente, o conceito de transculturação nasce com Turner já no fim do século XIX, marcando a passagem de um evolucionismo cientificista para uma chave cultural historicista, no contexto da busca pela singularidade das civilizações que haviam brotado e prosperado a oeste do oceano Atlântico. O conceito passou a integrar, aos poucos, os trabalhos de diversos historiadores e antropólogos latino-americanos durante primeira metade do século XX. Sua apropriação por teóricos da corrente pós-colonial é, portanto, tardia e marcada por uma notável atenuação das implicações dos meios físicos e econômicos em seu bojo.

A segunda referência que a corrente pós-colonial toma das teorias culturais desenvolvidas na América Latina é mais indireta: trata-se do conceito de comarca, desenvolvido pelo antropólogo brasileiro Darcy Ribeiro e também ressignificado por Ángel Rama nos seus estudos sobre os sistemas literários do continente. Com este

\footnotetext{
8 Apresentada na conferência de 1893 e intitulada "O significado da fronteira na história americana", influenciou, entre outros, o trabalho de Sérgio Buarque de Holanda em Caminhos e Fronteiras (1957).
} 
conceito, o uruguaio queria chamar a atenção às grandes áreas culturais (comarca pampeana, andina, caribenha, etc.) que ultrapassam as fronteiras políticas dos países. Com isso, e apoiado também pelo conceito de sistema literário, de Antonio Candido, Rama sobrepunha à geografia física e política uma geografia cultural, antecipando consideravelmente as preocupações das teorias do pós-colonialismo e buscando dar conta dos movimentos internos que uniam as diversas regiões da América Latina.

O que importa desta observação é o seguinte: se, por um lado, teóricos como Stuart Hall e Paul Gilroy adotaram o conceito de transculturação e criaram outros (quiçá complementares à comarca e válidos para se pensar as trocas simbólicas) como diáspora negra e Atlântico negro, por outro lado estes autores parecem ter retirado desses conceitos (inclusive daquele de transculturação) qualquer entendimento de uma força vetorial hegemônica, que impõe sua manifestação pelo sufocamento das culturas locais. Contra isso, vale lembrar que a afirmação da disparidade de forças integra o entendimento que Rama possuía tanto do processo de transculturação - quando pensa a dialética urbanarural e localista-cosmopolita - quanto da pujança relativa das literaturas das diversas comarcas que compõem o sistema literário latino-americano. Ou seja, sua visão sobre a dinâmica cultural - tal como a de Antonio Candido - buscava lastrear as bases econômicas e sociais, abandonadas ou ignoradas pelos teóricos pós-coloniais.

O que dá forma às relações entre nações ricas e pobres não são, em última instância, as questões da cor da pele ou identidade, mas sim do preço dos produtos primários, das matérias-primas, dos mercados de mão de obra, das alianças militares e das forças políticas. Em resumo, o pós-colonialismo tem sido, entre outras coisas, exemplo de um 'culturalismo' exuberante que (...) vem assolando a teoria cultural no Ocidente, enfatizando em demasia a dimensão cultural da vida humana. (EAGLETON, 1997, p. 324)

\section{Um culturalismo exuberante}

Nossa sugestão aqui é de que este "culturalismo exuberante" é, não um estilo ou uma escola, mas uma tendência: não somente na literatura, mas em diversos âmbitos da vida contemporânea, afetando em graus diferentes a produção artística e teórica. De fato, em seu livro sobre o pós-modernismo, Jameson argumenta que a lógica do sistema global, na contemporaneidade, é cultural, no sentido de que a cultura perpassa todos os âmbitos 
da vida cotidiana: da venda de shampoos étnicos à transformação da própria cultura em mercadoria ${ }^{9}$.

Parece-nos também que a ênfase "culturalista" como traço de uma literatura póscolonial - seja ela artística ou teórica - está relacionada ao que chamaremos de “consciência desarticulada do subdesenvolvimento". Nos remetemos aqui, obviamente, às formulações de Antonio Candido, em "Literatura e Subdesenvolvimento", ensaio de $1970^{10}$. Neste trabalho, o professor Candido trata de uma "consciência amena do atraso" que, ainda ao final do século XIX e início do XX, na América Latina, depositava na educação (como legado ideológico do Iluminismo europeu) a responsabilidade por reverter o atraso do continente frente à Europa e aos Estados Unidos. Posteriormente, por volta da década de 1930, começa a nascer o que Candido chama de "consciência catastrófica do subdesenvolvimento", que via - não mais na educação - mas na reestruturação econômica e social a única saída possível para o desenvolvimento latinoamericano.

Neste mesmo sentido, ao argumentarmos por uma "consciência desarticulada do subdesenvolvimento", gostaríamos de vincular o sentido da palavra desarticulação não somente a uma autonomia - que consideramos exagerada - do entendimento da própria cultura em relação aos fatores socioeconômicos fundamentais; senão também desarticulação na tentativa de resgate do próprio passado, como muitas vezes mencionado por autores como Mia Couto, José Luís Cabaço e, noutro âmbito, Frantz Fanon; desarticulação de um discurso do "multiculturalismo" que, ao se estender principalmente na Europa e nos Estados Unidos como suposto reconhecimento da alteridade, ignora, sob nosso ponto de vista, políticas protecionistas cada vez mais restritivas e cerceadoras no que concerne aos caracteres "território" e "população". Acima de tudo, a particularidade de ser mais velho do que o próprio país - reafirmada muitas vezes pelo escritor moçambicano Mia Couto - não é de fato uma experiência histórica tão específica e arrasadora do que ter vivido, em apenas meio século, em sequência direta, a violência e a pobreza de um colonialismo português retardatário; a violência e a pobreza de um socialismo já decadente; a violência e a pobreza de um capitalismo tardio ${ }^{11}$.

\footnotetext{
${ }^{9}$ Para um exemplo prático, vide o termo "economia criativa", na agenda dos ministros da Cultura do país há mais de uma década.

${ }^{10} \mathrm{O}$ ensaio integra o livro A Educação pela noite. Rio de Janeiro: Ouro sobre Azul, 2011.

11 “Os que, como eu, têm hoje quarenta e cinquenta anos já atravessaram realidades históricas muito diversas. Já foram de muitos Moçambiques." (COUTO, 2005, p. 86). "Sou moçambicano, filho de portugueses, vivi o sistema colonial, combati pela Independência, vivi mudanças radicais do socialismo ao
} 
$\mathrm{O}$ aspecto do atraso, comum às três experiências, sempre pressionou na direção dos métodos mais improvisados de implementação institucional; das formas mais duras de controle; das condições mais adversas de produção. Em nossa opinião, isto também compõe esta "consciência desarticulada do subdesenvolvimento", que encontra justamente no terreno da cultura um caminho - talvez mais estável e inteligível, talvez mais aceitável - para o resgate e a justificação de sua realidade contemporânea. Nesse sentido, gostaríamos de pensar o cultural para as ex-colônias portuguesas africanas (e outros países em situação correlata) não somente como um fator simultaneamente de trocas fronteiriças e de coesão nacional (pelo reconhecimento de sua "multiculturalidade" interna), senão também como fator histórico, cuja permanência - através de décadas tumultuadas e incertas - se revela talvez como único campo de certa continuidade reconhecível e, portanto, de sentido.

Walter Benjamin, em seu ensaio sobre Kafka, conta uma anedota sobre um mendigo que, em farrapos, narra para si mesmo uma história em que é um rei cujo vasto reino foi invadido, na calada da noite, por inimigos. Obrigado a partir às pressas, atravessando montanhas, florestas e vales perigosos, não tem tempo de levar consigo senão uma camisa velha: a mesma que está usando naquele momento. $\mathrm{O}$ mendigo se faz o rei refugiado, que se esconde agora numa taverna. Esta história que o mendigo conta para si mesmo - sugere Benjamin - é um dos subterfúgios deste pobre homem para apropriar-se de sua vida, para resgatar-se dignamente no presente, para justificar-se. É, enfim, de maneira análoga que vemos também o "culturalismo exuberante" no âmbito do pós-colonialismo.

\section{Referência bibliográfica:}

ABDALA JR., B. Um ensaio de abertura: mestiçagem e hibridismo, globalização e comunitarismos. In: BENJAMIN ABDALA JR. (Org.). Margens da Cultura: mestiçagem, hibridismo \& outras misturas. São Paulo: Boitempo Editorial, 2004. p. 13.

BHABHA, Homi. O local da cultura. Tradução de Eliana Lourenço de Lima Reis, Gláucia Renate Gonçalves, Myriam Ávila. Belo Horizonte: Editora UFMG, 2005.

capitalismo, da revolução à guerra civil. Nasci num tempo de charneira, entre um mundo que nascia e outro que morria." (idem, p. 106) 
COSTA, Iná Camargo. Palestra sobre o ensaio O Autor como Produtor. Marcos Soares e Maria Elisa Cevasco (orgs.). São Paulo: Humanitas, 2008.

EAGLETON, Terry. Teoria da literatura: uma introdução. Tradução de Waltensir Dutra. São Paulo: Martins Fontes, 1997.

GILROY, Paul. O Atlântico Negro: Modernidade e Dupla Consciência. Tradução de Cid Knipel Moreira. São Paulo/Rio de Janeiro: Editora 34/Universidade Cândido Mendes, 2001.

HALL, Stuart. Da Diáspora: identidades e mediações culturais. Tradução de Adelaine La Guardia Resende, Ana Carolina Escosteguy, Cláudia Álvares, Francisco Rüdiger. Belo Horizonte: Editora UFMG, 2003.

RAMA, Ángel. Literatura e Cultura na América Latina. In: AGUIAR, Flávio; VASCONCELOS; Sandra (Orgs.). São Paulo: Edusp, 2001.

RANCIÈRE, Jacques. O Ódio à Democracia. Tradução de Maria Echalar. São Paulo: Boitempo Editorial, 2014.

WEGNER, Robert. A Conquista do Oeste: A Fronteira na Obra de Sérgio Buarque de Holanda. Belo Horizonte: Editora UFMG, 2000.

WILLIAMS, Raymond. Marxismo e Literatura. Tradução de Waltensir Dutra. Rio de Janeiro: Zahar Editores, 1979.

WU, Chin-Tao. Privatização da cultura: a intervenção corporativa nas artes desde os anos 80. Tradução de Paulo Cesar Castanheira. São Paulo: Boitempo Editorial, 2006. 